\title{
Durum wheat grain and pasta from locally-grown crops: A case-study on Saragolla (Triticum turgidum ssp. turanicum) and Senatore Cappelli (Triticum turgidum ssp. durum) wheats
}

\author{
Rita Acquistucci*, Valentina Melini, Vincenzo Galli \\ Research Centre for Food and Nutrition, Council for Agricultural Research and Economics (CREA), Rome, Italy
}

\section{A B S T R A C T}

\begin{abstract}
The ancient grains Senatore Cappelli and Saragolla are often used as raw material, generally in mixture, for the production of pasta, which represents one of the most consumed foods in Italy. Due to the wide employment of these wheats in cereal based foods, it was found interesting to get information on the nutritional value of a food as widespread as pasta made by means of such wheats. In this study, long and short pasta samples produced from Saragolla and Senatore Cappelli were considered. Proximate chemical composition, starch digestibility and antioxidant compounds as well as cooking properties were studied. When the optimum cooking time is applied, pasta presents good sensory characteristics also thanks to the high protein content of raw material. Moreover, the employment of the durum whole meal in the pasta production, also guarantees a good level of bioactive compounds such as phenolic compounds.
\end{abstract}

Keywords: Pasta; Phenolic compounds; Saragolla, Senatore Cappelli; Starch digestibility

\section{INTRODUCTION}

An increasing demand for local food has been observed globally (Low et al., 2015). Actually, consumers perceive "local food" as the food of great quality in terms of freshness, taste, safety, animal welfare and environmental impacts (Jensen et al., 2019), alongside organic food.

The Lancet Commissions have recently stressed the urgency for producing and consuming locally-grown crops, as one among the strategies necessary to move from the actual food system production to a more sustainable one (Willett et al., 2019). The efforts made in the past 50 years to increase crop yields and improve production practices enabled reducing hunger and improving life expectancy indeed. However, environmental changes and ecosystem impairment, such as climate change, stratospheric ozone depletion, land degradation and desertification, biodiversity loss and freshwater depletion and contamination have been observed, as a possible effect of the aforementioned efforts (Whitmee et al., 2015).
A worldwide shift to unhealthy diets, high in calories and heavily-processed foods, was also reported (Springmann et al., 2016). Hence, the new frontier for scientists and policy-makers is turning to healthy diets from sustainable food systems.

Cereals and cereal-based products form the base of the food pyramid and the peak of the environmental pyramid. Nevertheless, most of the durum wheat products currently consumed are from modern wheat varieties, bred after the so-called "Green Revolution", in the 1960s. Durum wheat cultivars straw lines with high yield and improved technological quality were obtained by breeding (De Vita et al., 2007) and local wheat cultivars were side-lined because unsuited to intensive cultivation. Senatore Cappelli (T. turgidum ssp. durum) and Saragolla (T. turgidum ssp. turanicum) are traditional durum wheats from Southern Italy characterized by high quality semolina but unsuitable to intensive farming. They are generally considered "ancient grains" because they had never undergone modern plant breeding programmes. 
Senatore Cappelli was obtained by selecting individual lines from Italian, Syrian-Palestinian and North African landraces. It is characterized by wide adaptability also in marginal areas, although it lodges easily and this characteristic makes it difficult to harvest. Anyway, it presents excellent level of protein, dietary fiber and antioxidants (Dinelli et al., 2013). Saragolla is an Italian crop of Khorasan introduced in Abruzzi (Italy) in AD 400. It is generally resistant to diseases and with a high content in proteins and gluten. The Saragolla wheat owes its rediscovery to the sudden success of the Kamut ${ }^{\circledR}$, a registered trademark which represents a specific and ancient variety of grain (T. turgidum ssp. turanicum, commonly called khorasan) registered by USDA in 1990. Over time, Khorasan wheat, and consequently Saragolla, has become the subject of attention as an alternative to Kamut ${ }^{\circledR}$, thanks to its genetic similarity and to its nutritional and technological properties without the limits of a registered trademark (Grausgruber et al., 2004).

Most scientific research, concerning ancient grains, is mainly referred to wheat plants such as einkorn, emmer, spelta and buckwheat. These papers explore aspects related to their technological characteristics (Bonafaccia and Kreft, 1994; D’Egidio and Vallega, 1994; Marconi et al., 1999; Galterio et al., 2003; Pasqualone et al., 2011; Hidalgo and Brandolini, 2012; Mefleh et al., 2019) and nutritional properties (Acquistucci and Fornal, 1997; Hidalgo et al., 2006; Hidalgo and Brandolini 2014; Dinu et al., 2018, Malalgoda et al., 2019).

Because of the success obtained by Kamut ${ }^{\circledR}$, some authors have dealt with the Khorasan Kamut wheat and papers concerning the agronomic traits (Grausgruber et al., 2004; Michalcova et al., 2014) and nutritional and technological applications (Bordoni et al., 2017; Boukid et al., 2018; Trozzi et al., 2019) appeared in recent times. However, other Khorasan wheats, such as Saragolla, are poorly studied because they have not the same reputation as the Kamut, though their use in processed foods is gradually increasing.

Consumers continue to push for better, cleaner, more nutritious products, and producers move towards creating foods that have higher nutritional value by incorporating ancient grains, which are a more sustainable crop. Senatore Cappelli and Saragolla are widely used to produce cereal based foods and, for this reason, it was found interesting to get information on the nutritional value of one of the most popular and appreciated food such as pasta.

In this context, grains Senatore Cappelli and Saragolla, grown in the same place and period in Central Italy, were used to produce pasta samples. Chemical composition as well as phenolic compounds were detected in grains and pasta samples while sensory characteristics were evaluated on cooked pasta. Moreover, some nutritional parameters such as starch digestibility were evaluated on uncooked and cooked pasta.

\section{MATERIALS AND METHODS}

\section{Chemicals and reagents}

Sodium carbonate, Folin-Ciocalteu reagent, methanol, acetone, ethyl acetate, and gallic acid were purchased from Carlo Erba (Milan, Italy). Total starch and resistant starch assay kits were obtained from Megazyme (Astori Tecnica S.n.c, Brescia, Italy).

\section{Sample preparation}

Durum wheat grains of Saragolla (G1) and Senatore Cappelli (G2) were provided by a farm located in Central Italy (Contigliano-Rieti). Chemical analyses were performed on samples reduced to fine particles $(<0.5 \mathrm{~mm})$ by a watercooled mill (Janke and Kunkel IKA LabortechniK, Staufen, Germany).

A sample of short pasta (penne) and long pasta (spaghetti diameter $2.7 \mathrm{~mm}$ ) were prepared from a mixture of the wholemeal flour of Saragolla and Senatore Cappelli (2:1) in an artisanal pasta maker located in Pianella (Pesaro, Italy). Maximum drying temperature was $40^{\circ} \mathrm{C}$ for both samples; the short pasta was dried for 36 hours and the long pasta for 60 hours.

\section{Grain quality parameters}

Grains of the same cultivar were grouped together and a sample of about $2 \mathrm{~kg}$ was cleaned and used to assess grain quality. Thousand kernel weight (TKW) was determined by counting and weighing three sets of 1,000 kernels for each sample (ISO, 2010). Test Weight (TW) was determined by a Shopper chondrometer equipped with a $250 \mathrm{~mL}$ cylinder according to the ISO method 7971 (2009). The result is expressed in kilograms per hectoliter (kghL).

Grain moisture and protein content $(\mathrm{Nx} 5.70)$ were determined according to the ICC Standard methods (ICC, 2003). Total lipids were determined according to the Metodi Ufficiali di Analisi (1994) and ash content to the ISO method 2171 (2007). Protein, ash and fat content are expressed as $\mathrm{g} / 100 \mathrm{~g}$ on a dry matter basis (d.m). Moisture is reported as $\mathrm{g} / 100 \mathrm{~g}$ fresh weight (f.w.).

\section{Pasta cooking}

Pasta was cooked as follows: $25 \mathrm{~g}$ of dry pasta was boiled into $250 \mathrm{~mL}$ of distilled water. Each pasta sample was cooked to its optimal cooking time (defined as the time required for the white core in the center of the pasta strand to disappear). Preliminarily, optimum-cooking time was 
assessed by removing a sample from the cooking water every 30 seconds.

After the sample was taken, it was pressed between two Plexiglas plates. Subsequently, the cooked pasta was left to cool for 25 minutes at room temperature and weighed.

\section{Cooking behavior}

Dry matter (DM), Water absorption (WA) and Swelling index (SI) were evaluated by drying cooked pasta at $105^{\circ} \mathrm{C}$ to constant weight. Cooking loss (CL) was evaluated evaporating to dryness at $110^{\circ} \mathrm{C}$ the rinse water released after cooking (Gelencsér et al., 2008). DM, WA and CL are reported as $\mathrm{g} / 100 \mathrm{~g}$ of sample.

\section{Total polyphenol content (TPCs)}

Extractable phenolic compounds (EPCs) and nonextractable phenolic compounds (NEPCs) were determined as reported in Acquistucci et al. (2018). Briefly, a sample amount (about $1.0 \mathrm{~g}$ ) was extracted with acidified aqueous methanol (50:50, $\mathrm{pH}: 2.0)$, and after the removal of the upper phase, it was re-extracted by acetone: water $(70: 30 \mathrm{v} / \mathrm{v})$ under magnetic stirring at room temperature for 1 hour. The recovered supernatants were labelled EPCs and quantified by the Folin-Ciocalteu colorimetric assay, as detailed in Melini and Acquistucci (2017). The residue, after the EPCs extraction, was hydrolyzed under ultrasound irradiation for 90 minutes with $\mathrm{NaOH} 2 \mathrm{M}$ and then extracted with ethyl acetate. The NEPCs were quantified by Folin-Ciocalteu reaction as previously reported for EPCs.

Gallic acid was used as a standard and results are expressed as mg of gallic acid equivalents (GAE) per $100 \mathrm{~g}$ of sample d.m.

\section{Starch digestibility of pasta samples}

Total starch content (TS) was determined in uncooked and cooked pasta (McCleary et al., 1997). Cooked samples were left for few minutes at room temperature to cool, then they were cut into small pieces and weighed. Samples, were added with $2 \mathrm{~mL}$ of dimethyl sulfoxide and the suspension was placed into a boiling bath for 5 minutes. Afterwards, the sample was incubated with thermostable $\alpha$-amylase for 6 minutes in a boiling water bath followed by amyloglucosidase (AMG) stirred on a vortex mixer and incubated at $50^{\circ} \mathrm{C}$ for 30 minutes. Once the enzyme hydrolysis was over, the solution was transferred into a $100 \mathrm{~mL}$ volumetric flask and the volume adjusted with distilled water. After a centrifugation at 3,000 rpm for 10 minutes, aliquots of solution $(0.1 \mathrm{~mL})$, containing glucose, were left to react with the oxidase/peroxidase (GOPOD) reagent and the readings were carried out at $510 \mathrm{~nm}$ against a blank. A glucose standard solution was used as a control. To quantify starch from glucose content, a conversion factor was used. Results are expressed as $\mathrm{g} / 100 \mathrm{~g}$ d.m.

Resistant starch (RS) was determined in uncooked and cooked pasta (McCleary et al., 2002). As previously reported for TS, cooked samples were left to cool for few minutes, cut into small pieces and weighed. In addition, to simulate chewing, few glass balls were introduced in each vial while stirring.

For the determination of RS, each sample (uncooked and cooked pasta) was incubated with pancreatic $\alpha$-amylase containing amyloglucosidase (AMG) for 16 hours at $37^{\circ} \mathrm{C}$ under continuous shaking (200 strokes/min). After the portion of non-resistant starch was removed, the RS pellet was dissolved in $2 \mathrm{M} \mathrm{KOH}$ and stirred for about 20 minutes in an ice water bath. Then, the RS hydrolysis was performed by using $0.1 \mathrm{~mL}$ of AMG in sodium acetate buffer $(\mathrm{pH}=3.8)$ at $50^{\circ} \mathrm{C}$ for 30 minutes. For the quantitative determination, the procedure already described for TS was followed. A RS standard was used as a control.

Digestible starch (DS) was calculated as the difference between TS and RS. Results are reported as $\mathrm{g} / 100 \mathrm{~g}$ d.m.

\section{Statistical analysis}

Results are the average of at least three determinations. Student T-test was used to compare mean values among samples of the same kind. A value of $p<0.05$ was considered statistically significant.

\section{RESULTS AND DISCUSSION}

\section{Physical and chemical properties of grains}

To evaluate the physical characteristics of grains, TKW and TW were determined and results are reported in Table 1. TKW and TW, which can be used to predict potential flour yield, are recognized as principal quality parameters by milling industry. TKW is the weight in grams of 1,000 seeds and variation in TKW of different grains may be attributed to a varietal characteristic which is influenced by the size of the grains and moisture content (Balasubramanian and Viswanathan, 2010). TKW is not only related to milling quality of grain, but it has a relation with the seedling growth and vigour which indirectly affect the yield (Botwright, 2002). Our sample showed TKW values of $61.1 \mathrm{~g}$ for G1 and $49.3 \mathrm{~g}$ for G2. Wrigley et al. (2016) reported as acceptable TKW values from $38 \mathrm{~g}$ and $45 \mathrm{~g}$ : in both our samples this index exceeded such values so describing good quality kernels.

TW is recognized worldwide as a measure of the grain packing density affected by grain size and shape. Grain soundness and values higher than $76 \mathrm{kghL}^{-1}$ are highly 
desirable (Wrigley et al., 2016). Our samples showed TW values of $75.0 \mathrm{~kg} \mathrm{hL}$ for $\mathrm{G} 1$ and $77.0 \mathrm{~kg} \mathrm{hL}$ g for G2, respectively. From these data, we can conclude that our samples were well developed and free from adverse events such as insect damage, heat stress or delayed harvesting (Deivasigamani and Swaminathan, 2018).

Protein content was 13.8 and $14.3 \mathrm{~g} / 100 \mathrm{~g} \mathrm{d.m}$. and ash content was 2.0 and $2.1 \mathrm{~g} / 100 \mathrm{~g}$ d.m. in the sample G1 and $\mathrm{G} 2$ respectively. These values are in the range generally found in whole wheat grains.

Lipid content is not considered a marker of grain quality being only $1 \%-3 \%$ of chemical components of grains. Durum wheat kernels contain about 2.4-3.8 g/100 g d.m. Two thirds of them are in the germ, $15 \%$ in the bran and about $20 \%$ are distributed in the endosperm (Lafiandra et al., 2012). In our samples, total lipid content was $2.3 \mathrm{~g} / 100 \mathrm{~g}$ d.m. in $\mathrm{G} 1$ and $2.2 \mathrm{~g} / 100 \mathrm{~g}$ d.m. in G2 in agreement with results found by other authors (Bordoni et al., 2017).

\section{Chemical composition and cooking quality characteristics of pasta samples}

Chemical composition of uncooked pasta samples and the corresponding cooking quality are illustrated in Table 2. As far as uncooked pasta is concerned, no statistical differences $(p<0.05)$ were found in the chemical composition. As concerns the cooking quality, this is defined by the capacity of pasta to maintain shape and good texture after cooking, avoiding becoming sticky; more in general, the cooking quality of durum pasta can be assessed by the extent of leaching into the cooking water. The cooking performances of samples under investigation were studied through the evaluation of parameters such as CL, WA, SI and DM. CL values reflect the quantity of starch and other solid matter that are released into the cooking medium from the pasta protein matrix (Cole,1991). The CL values were $4.9 \mathrm{~g} / 100 \mathrm{~g}$ and $6.0 \mathrm{~g} / 100 \mathrm{~g}$ in penne and spaghetti samples, respectively. Padalino et al. (2015) found higher CL in whole meal Saragolla (7.05 g/100 g) compared to semolina spaghetti $(6.20 \mathrm{~g} / 100 \mathrm{~g})$ and they related this behavior to the high fiber content in the first sample that is able to favor greater amount of gelatinized starch to leach from pasta during cooking. Manthey et al. (2004) observed in spaghetti added with buckwheat bran flour a decrease of CL while increasing the drying temperature. Drying temperature denatures proteins associated with the gluten matrix, especially when it is higher than $60^{\circ} \mathrm{C}$, which subsequently protects starch granules from rupturing during cooking (Mefleh et al., 2019). Samples examined in this study were prepared by using the same raw material: therefore, differences observed in the CL values can be reasonably attributed to the drying diagram in terms of time and temperature applied.

SI and WA were also calculated in both samples. From data illustrated in Table 2, it results that WA reflected the same trend observed for SI and discussed for CL: in fact, spaghetti samples showed higher values for all the indices with respect to penne. WA was $100.0 \mathrm{~g} / 100 \mathrm{~g}$ for penne and $137.3 \mathrm{~g} / 100 \mathrm{~g}$ for spaghetti, while SI was 1.11 and $1.77 \mathrm{for}$ penne and spaghetti respectively. As reported by Padalino

Table 1: Some physical and chemical characteristics of grains ${ }^{* 1}$

\begin{tabular}{|c|c|c|c|c|c|c|c|}
\hline Sample & Label & $\frac{\text { TKW }}{g}$ & $\begin{array}{c}\text { TW } \\
\text { kg hL }\end{array}$ & $\begin{array}{c}\text { Protein } \\
\text { g/100 g d.m. }\end{array}$ & $\begin{array}{c}\text { Ash } \\
\mathrm{g} / 100 \mathrm{~g} \mathrm{d.m} .\end{array}$ & $\frac{\text { Fat }}{\mathrm{g} / 100 \mathrm{~g} \text { d.m. }}$ & $\begin{array}{c}\mathrm{CHO}^{2} \\
\mathrm{~g} / 100 \mathrm{~g} \mathrm{~d} . \mathrm{m} .\end{array}$ \\
\hline Saragolla & G1 & $61.1^{\mathrm{a}}$ & $75.0^{a}$ & $13.8^{a}$ & $2.0^{\mathrm{a}}$ & $2.3^{a}$ & 81.9 \\
\hline Senatore Cappelli & G2 & $49.3^{b}$ & $77.0^{\mathrm{b}}$ & $15.0^{b}$ & $2.1^{\mathrm{a}}$ & $2.2^{\mathrm{a}}$ & 80.7 \\
\hline
\end{tabular}

*Data are the average of at least three replicate measurements

${ }^{1}$ Values with different superscript letters within the same column are significantly different $(p<0.05)$

${ }^{2}$ Total carbohydrates: data are calculated as a difference

Table 2: Chemical composition of uncooked pasta and cooking quality of cooked samples. Cooking time (CT), dry matter (DM), water absorption (WA), swelling index (SI) and cooking loss (CL) ${ }^{\star 1}$

\begin{tabular}{|c|c|c|c|c|c|}
\hline \multicolumn{6}{|c|}{ Chemical Composition } \\
\hline Sample & Moisture & Protein & Fat & Ash & $\mathrm{CHO}^{2}$ \\
\hline & $\mathrm{g} / 100 \mathrm{~g}$ f.w. & g/100 g d.m. & g/100 g d.m. & g/100 g d.m. & g/100 g d.m. \\
\hline Penne (uncooked) & $10.8^{a}$ & $13.9^{\mathrm{a}}$ & $2.2^{\mathrm{a}}$ & $1.5^{\mathrm{a}}$ & 83.0 \\
\hline Spaghetti (uncooked) & $11.0^{\mathrm{a}}$ & $13.7^{\mathrm{a}}$ & $2.1^{\mathrm{a}}$ & $1.6^{\mathrm{a}}$ & 83.3 \\
\hline \multicolumn{6}{|c|}{ Cooking Quality Characteristics } \\
\hline & CT & DM & WA & SI & CL \\
\hline & $\min$ & $\%$ & $\%$ & & $\%$ \\
\hline Penne (cooked) & 8 & $42.7^{a}$ & $110.2^{a}$ & $1.11^{a}$ & $4.9^{\mathrm{a}}$ \\
\hline Spaghetti (cooked) & 7 & $36.1^{b}$ & $137.3^{b}$ & $1.77^{\mathrm{b}}$ & $6.0^{\mathrm{b}}$ \\
\hline
\end{tabular}

*Data are the average of at least three replicate measurements

${ }^{1}$ Values with different superscript letters within a column are significantly different $(p<0.05)$

${ }^{2}$ Total carbohydrates: data are calculated as a difference 
et al. (2015), whole meal spaghetti generally showed lower SI and WA when compared to pasta from semolina because bran competes with starch for water. The same authors also detected a greater CL in wholemeal spaghetti compared to semolina spaghetti: they attributed this behaviour to the fiber that is able to interfere with the formation of protein network so producing a loss of continuity of the pasta matrix. Our pasta samples were produced by using the same raw material and, again, we can apply the same considerations previously made.

\section{Carbohydrate content in uncooked and cooked pasta samples}

Pasta is a staple food and one of the major sources of carbohydrates. Despite it provides refined carbohydrates, it has a low glycemic index and it has been reported that it has no adverse effect on body weight and body mass index, in the context of low glycemic index dietary patterns (Chiavaroli et al., 2018). As a matter of fact, the compacted and dense structure of extruded pasta, alongside the gluten matrix, closely adheres to starch granules preventing the access of $\alpha$-amylase. Hence, the digestion is low and the release of glucose is gradual (Fardet et al., 1999).

In this study, TS and DS were determined in uncooked and cooked pasta samples (Fig. 1). TS values were about $75 \mathrm{~g} / 100 \mathrm{~d} \cdot \mathrm{m}$ ( $>90 \%$ of total carbohydrates) and result are comparable in both pasta samples. In uncooked pasta, DS was $66.8 / 100 \mathrm{~g} \mathrm{~d} . \mathrm{m}$. and $68.0 \mathrm{~g} / 100 \mathrm{~g} \mathrm{~d} . \mathrm{m}$. in penne and spaghetti respectively. After cooking, these values increased to $72.0 \mathrm{~g} / 100 \mathrm{~g} \mathrm{~d} . \mathrm{m}$ and $73.2 \mathrm{~g} / 100 \mathrm{~g}$ d.m. in penne and spaghetti. In uncooked pasta, about $5 \mathrm{~g} / 100 \mathrm{~g}$ d.m. was found not available for the absorption (resistant starch). It can comprise starch granules encapsulated by cell wall or in protein network and not fully gelatinized (Miao et al.,

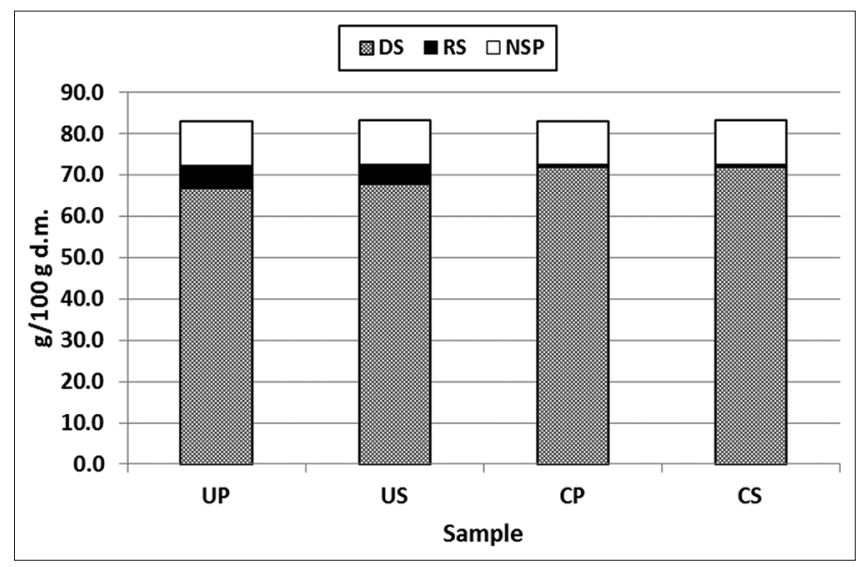

Fig 1. Digestible starch (DS) ${ }^{1}$, resistant starch (RS) and non-starch polysaccharides $(\mathrm{NSP})^{2}$ in uncooked and cooked pasta (g/100 g d.m.) ${ }^{1}$ calculated as a difference between TS and RS ${ }^{2}$ calculated as a difference between $\mathrm{CHO}$ and DS plus RS 'UP- uncooked penne, US-uncooked spaghetti, CP- cooked penne, CS-cooked spaghetti
2009) or bound to lipid or protein in a complex formation (Casiraghi et al., 1992). This fraction was strongly reduced after cooking (about $0.5 \%$ ) because of the increasing susceptibility of starch to $\alpha$-amylase hydrolysis as observed by Garcia-Alonso et al. (1999).

The difference between total carbohydrates (CHO) and starch content (DS+RS) is classified as non-starch polysaccharides (NSP). This fraction, which was about $11.0 \mathrm{~g} / 100 \mathrm{~g}$ d.m., is expected in view of the high ash content of the samples considered.

\section{Comparison of the phenolic compounds content in grains and pasta}

Alongside providing the major caloric and protein intake, whole grains contain significant amounts of phenolic compounds which have protective effects against chronic oxidative stress-related diseases (Del Rio et al., 2013; Van Hung, 2016), such as cardiovascular diseases and cancer (Carocho \& Ferreira, 2013; Rangel-Huerta et al., 2015). These antioxidants can be found both in extractable and non-extractable form (Pérez-Jiménez and Torres, 2011) and they are commonly referred to as extractable phenolic compounds (EPCs) and non-extractable phenolic compounds (NEPCs). In wheat, the latter is the major fraction of phenolic compounds (Acosta-Estrada et al., 2014), and despite their content has been underestimated for a long time (Adom and Liu, 2002), they are important from a nutritional point of view because they can be hydrolyzed in the small intestine by intestinal enzymes and become bioavailable. Moreover, they may reach the colon, nearly intact, and may be transformed by the colonic microflora into small phenolic metabolites (Pérez-Jiménez and Torres, 2011). In view of their health effects, both EPCs and NEPCs were determined in this study. These bioactive molecules were evaluated in grains and pasta samples in order to assess the effect of pasta making on the content thereof.

The content of EPCs and NEPCs is reported in Table 3, alongside their percentage with respect to total phenolic content (TPCs). In grains G1, the EPCs content was higher than in G2, while NEPCs content was comparable. In grains NEPCs represented the major phenolic fraction (58\% for G1 and 69\% for G2), in keeping with literature data reporting phenolics mostly occurring in the bound form (Van Hung, 2016).

As far as uncooked pasta samples are concerned, penne and spaghetti showed lower TPCs respect to grains but comparable EPCs (106.6-114.8 mg GAE/100 g d.m.) and NEPCs (120.0-115.5 mg GAE/100 g d.m.) values. As regards TPCs, the difference between grains and pasta is due to the extraction rate of raw material used for pasta production, which produces the removal of the external 
Table 3: Phenolic content in grains and uncooked pasta products*. Extractable phenolic compounds (EPCs), non-extractable phenolic compounds (NEPCs), total phenolic compounds (TPCs) and relative percentage ${ }^{1}$

\begin{tabular}{|c|c|c|c|c|c|}
\hline Sample & $\begin{array}{c}\text { EPCs } \\
\text { mg GAE/100 g d.m. }\end{array}$ & $\begin{array}{c}\text { NEPCs } \\
\text { mg GAE/100 g d.m. }\end{array}$ & $\begin{array}{c}\text { TPCs } \\
\text { mg GAE/100 g d.m. }\end{array}$ & $\frac{\text { EPCs }}{\%}$ & $\frac{\text { NEPCs }}{\%}$ \\
\hline G1 & $173.2^{\mathrm{a}}$ & $243.9^{a}$ & $417.1^{\mathrm{a}}$ & 42 & 58 \\
\hline G2 & $109.7^{b}$ & $249.6^{a}$ & $359.3^{b}$ & 31 & 69 \\
\hline Penne & $106.6^{a}$ & $120.0^{a}$ & $226.6^{a}$ & 47 & 53 \\
\hline Spaghetti & $114.8^{a}$ & $115.5^{\mathrm{a}}$ & $230.3^{a}$ & 50 & 50 \\
\hline
\end{tabular}

*Data are the average of at least three replicate measurements

${ }^{1}$ Calculated respect to the total phenolic content

layers of kernels as shown by low ash content respect to grains (Tables 1 and 2). Compared to grains, the different distribution of EPCs and NEPCs in pasta, where the two fractions tend to match, can be due to pasta making process which promotes the disruption of linkage between phenolic compounds and the food matrix components, so making phenolic compounds easily extractable and producing a shift from the bound to the free form, as already observed by some authors (Dewanto et al., 2002). Contradictory results have been reported concerning the distribution of phenolic compounds in pasta. Comparing semolina and durum wheat pasta, enriched with bran fractions, Fares et al. (2010) observed a decrease in free phenolic acids without any change in the bound fraction. After cooking, the same authors observed that bound phenolic acids increased because of boiling that enhances the bound phenolic extraction from the food matrix. De Paula et al. (2017) found that some steps of pasta processing such as mixing and extrusion reduced free phenolic acids in fresh and uncooked pasta formulations but the decrease was almost entirely borne by ferulic, caffeic and, to a lesser extent, to p-hydroxybenzoic acids. To explain the contradictory results reported in the literature, some considerations must be done. The first of them is that during pasta processing, oxygen, water and heat treatment induce the oxidative degradation of antioxidants (Borrelli et al., 1999) and the drying process affects to a different extent the phenolic acids in the free and bound fraction (De Paula et al., 2017). As a consequence, the different phenolic acid composition of the sample and the drying conditions applied both affect the TPCs.

Moreover, it must be also recognized that polarities of different phenolic compounds vary significantly due to their conjugation status and their association in the matrix (Perez-Jimenez and Torres, 2011): therefore the analytical procedure applied to extract phenolic compounds strongly determine the final result.

\section{CONCLUSIONS}

Grains showed a high protein amount that surely contributes to the final quality of products. When the optimum cooking time is applied, the cooking quality parameters describe pasta of good sensory characteristics. In pasta samples, a significant content of phenolic compounds has been found which can improve the possible benefits in diet. Moreover, in cooked pasta about $90 \%$ of starch resulted digestible.

Hence, the study provides the basis for further investigations into the adaptability of durum wheat genotypes to lowinput agriculture and into the identification of varieties best suited to local food systems.

\section{ACKNOWLEDGEMENTS}

The authors wish to acknowledge Dr. M. Luchetti for providing the samples. This research was financially supported by the Italian Ministry "Ministero delle Politiche Agricole, Alimentari e Forestali (MiPAAF)" in the framework of the Project TERRAVITA.

\section{Conflict of interest}

The authors declare no conflict of interest

\section{Authors' contribution}

AR designed the study and planned the experiments. AR, VM and VG performed the experiments and analyzed the data. AR drafted the manuscript and VM contributed to the revision.

\section{REFERENCES}

Acosta-Estrada, B. A., J. A. Gutiérrez-Uribe and S. O. Serna-Saldívar. 2014. Bound phenolics in food a review. Food Chem. 152: 46-55.

Acquistucci, R. and J. Fornal. 1997. Italian buckwheat (Fagopyrum esculentum) starch: Physico-chemical and functional characterization and in vitro digestibility. Nahrung. 41: 281-284.

Acquistucci, R., V. Melini, I. Garaguso and F. Nobili. 2018. Effect of bread making process on bioactive molecules in durum wheat bread and assessment of antioxidant properties by Caco-2 cell culture model. J. Cereal Sci. 83: 188-195.

Adom, K. K. and R. H. Liu. 2002. Antioxidant activity of grains. J. Agric. Food Chem. 50: 6182-6187.

Balasubramanian, S. and R. Viswanathan. 2010. Influence of moisture content on physical properties of minor millets. J Food Sci. Technol. 47: 279-284.

Bonafaccia, G. and I. Kreft. 1994. Technological and qualitative characteristics of food products made with buckwheat. Fagopyrum. 14: 35-42. 
Bordoni, A., F. Danesi, M. Di Nunzio, A. Taccari and V. Valli. 2017. Ancient wheat and health: A legend or the reality? A review on KAMUT Khorasan wheat. Int. J. Food Sci. Nutr. 68: 278-286.

Borrelli, M. G., A. Troccoli, N. Di Fonzo and C. Fares. 1999. Durum wheat lipoxygenase activity and other quality parameters that affect pasta color. Cereal Chem. 76: 335-340.

Botwright, T. L., A. G. Condon, G. J. Rebetzke and R. A. Richards. 2002. Field evaluation of early vigour for genetic improvement of grain yield in wheat. Aust. J. Agric. Res. 53: 1137-1145.

Boukid, F., S. Folloni, S. Sforza, E. Vittadini and B. Prandi. 2018. Current trends in ancient grains-based foodstuffs: Insight into nutritional aspects and technological applications. Compr. Rev. Food Sci. Food Saf. 17: 123-134.

Carocho, M. and I. C. F. Ferreira. 2013. A review on antioxidants, pro-oxidants and related controversy: Natural and synthetic compounds, screening and analysis methodologies and future perspectives. Food Chem. Toxicol. 51: 15-25.

Casiraghi, M. C., F. Brighenti and G. Testolin. 1992. Lack of effect of high temperature drying on digestibility of starch in spaghetti. J. Cereal Sci. 15: 165-174.

Chiavaroli, L., C. W. C. Kendall, C. R. Braunstein, S. B. Mejia, L. A. Leiter, D. J. A. Jenkins and J. L. Sievenpiper. 2018. Effect of pasta in the context of low-glycaemic index dietary patterns on body weight and markers of adiposity: A systematic review and meta-analysis of randomised controlled trials in adults. BMJ Open. 8(3): e019438.

Cole, M. E. 1991. Review: Prediction and measurement of pasta quality. Int. J. Food Sci. Technol. 26: 133-151.

D'Egidio, M. G. and V. Vallega. 1994. Bread baking and dough mixing quality of diploid wheat Triticum monococcum L. Ital. Food Bev. Technol. 4: 6-9.

Deivasigamani, S. and C. Swaminathan. 2018. Evaluation of seed test weight on major field crops. Int. J. Res. Stud. Agric. Sci. 4: 8-11.

Del Rio, D., A. Rodriguez-Mateos, J. P. E. Spencer, M. Tognolini, G. Borges and A. Crozier. 2013. Dietary (poly) phenolics in human health: Structures, bioavailability, and evidence of protective effects against chronic diseases. Antioxid. Redox Signal. 18: 1818-1892.

De Paula, R., I. Rabalski, M. C. Messia, E. S. M. Abdel-Aal and E. Marconi. 2017. Effect of processing on phenolic acids composition and radical scavenging capacity of barley pasta. Food Res. Int. 102: 136-143.

De Vita, P., O. Li Destri Nicosia, F. Nigro, C. Platani, C. Riefolo, N. Di Fonzo and L. Cattivelli. 2007. Breeding progress in morphophysiological, agronomical and qualitative traits of durum wheat cultivars released in Italy during the $20^{\text {th }}$ century. Eur. J. Agron. 26: 39-53.

Dewanto, V., X. Wu, K. K. Adom and R. H. Liu. 2002. Thermal processing enhances the nutritional value of tomatoes by increasing total antioxidant activity. J. Agric. Food Chem. 50: $3010-3014$

Dinelli, G., I. Marotti, R. Di Silvestro, S. Bosi, V. Bregola, M. Accorsi, A. Di Loreto, S. Benedettelli, L. Ghiselli and P. Catizone. 2013. Agronomic, nutritional and nutraceutical aspects of durum wheat (Triticum durum Desf.) cultivars under low input agricultural management. Ital. J. Agron. 8: 85-93.

Dinu, M., A. Whittaker, G. Pagliai, S. Benedettelli and F. Sofi. 2018. Ancient wheat species and human health: Biochemical and clinical implications. J. Nutr. Biochem. 52: 1-9.

Fardet, A., J. Abecassis, C. Hoebler, P. M. Baldwin, A. Buléon, S. Bérot and J. L. Barry. 1999. Influence of technological modifications of the protein network from pasta on in vitro starch degradation. J. Cereal Sci. 30: 133-145.
Fares, C., C. Platani, A. Baiano and V. Menga. 2010. Effect of processing and cooking on phenolic acid profile and antioxidant capacity of durum wheat pasta enriched with debranning fractions of wheat. Food Chem. 119: 1023-1029.

Galterio, G., P. Codianni, A. M. Giusti, B. Pezzarossa and C. Cannella. 2003. Assessment of the agronomic and technological characteristics of Triticum turgidum ssp dicoccum Schrank and and T. spelta L. Nahrung. 1: 54-59.

Garcia-Alonso, A., A. Jimenez-Escrig, N. Martin-Carron, L. Bravo and F. Saura-Calixto. 1999. Assessment of some parameters involved in the gelatinization and retrogradation of starch. Food Chem. 66: 181-187.

Gelencsér, T., V. Gál, M. Hódsági and A. Salgó. 2008. Evaluation of quality and digestibility characteristics of resistant starchenriched pasta. Food Bioprocess Tech. 1: 171-179.

Grausgruber, H., C. Sailer and P. Ruckenbauer. 2004. Khorasan wheat, Kamut $\AA$ and "pharaonenkorn": Origin, characteristics and potential. Vereinigung Pflanzenzuchter Saatgutkaufleute Osterreichs. 55: 75-80.

Hidalgo, A. and A. Brandolini. 2012. Lipoxygenase activity in whole meal flours from Triticum monococcum, Triticum turgidum and Triticum aestivum. Food Chem. 131: 1499-503.

Hidalgo, A. and A. Brandolini. 2014. Nutritional properties of einkorn wheat (Triticum monococcum L.). J. Sci. Food Agric. 94: 601-612.

Hidalgo, A., A. Brandolini, C. Pompei and R. Piscozzi. 2006. Carotenoids and tocols of einkorn wheat (Triticum monococcum ssp. monococcum L.). J. Cereal Sci. 44: 182-193.

ICC. 2003. International Association for Cereal Science and Technology, Vienna, Austria.

ISO. 2007. Determination of ash yield by Incineration Method 2171. International Organization for Standardization, Geneva, Switzerland.

ISO. 2009. Determination of Bulk Density, Called Mass per Hectoliter Method 7971. International Organization for Standardization, Geneva, Switzerland.

ISO. 2010. Determination of the Mass of 1000 Grains Method 520. International Organization for Standardization, Geneva, Switzerland.

Jensen, J. D., T. Christensen, S. Denver, K. Ditlevsen, J. Lassen and R. Teuber. 2019. Heterogeneity in consumers' perceptions and demand for local (organic) food products. Food Qual. Prefer. 73: $255-265$.

Lafiandra, D., S. Masci, M. Sissons, E. Dornez, J. A. Delcour, C. M. Courtin and M. F. Caboni. 2012. Kernel components of technological value. In: M. Sissons, B. Marchylo, J. Abecassis and M. Carcea. (Eds.), Durum Wheat Chemistry and Technology. $2^{\text {nd }}$ ed. AACC International Inc., St. Paul, MN, USA, pp. 85-124.

Low, S., A. Adalja, E. Beaulieu, N. Key, S. Martinez, A. Melton, A. Perez, K. Ralston, H. Stewart, S. Suttles and B. Jablonski. 2015. Trends in U.S. Local and Regional Food Systems: A Report to Congress. Economic Research Report No. AP 068. U.S. Department of Agriculture, Washington, DC, United States.

Malalgoda, M., J. B. Ohm and S. Simsek. 2019. Celiac antigenicity of ancient wheat species. Foods. 8: 675-680.

Manthey, F. A., S. R. Yalla, T. J. Dick and M. Badaruddin 2004. Extrusion properties and cooking quality of spaghetti containing buckwheat bran flour. Cereal Chem. 81: 232-236.

Marconi, E., M. Carcea, M. Graziano and R. Cubadda. 1999. Kernel properties and pasta-making quality of five European spelt wheat (Triticum spelta L.) cultivars. Cereal Chem. 76: 25-29.

McCleary, B. V., T. S. Gibson and. D. C. Mugford. 1997. Measurement of total starch in cereal products by amyloglucosidase- $\alpha$-amylase 
method: Collaborative study. J. AOAC Int. 80: 571-579.

McCleary, B. V., M. McNally and P. Rossiter. 2002. Measurement of resistant starch by enzymic digestion in starch samples and selected plant materials: Collaborative study. J. AOAC Int. 85: 1103-1111.

Mefleh, M., P. Conte, C. Fadda, A. Piga, G. Hassoun and R. Motzo. 2019. From ancient to old and modern durum wheat varieties: Interaction among cultivar traits, management, and technological quality. J. Sci. Food Agric. 99: 2059-2067.

Melini, V. and R. Acquistucci. 2017. Health-promoting compounds in pigmented Thai. Foods. 6: 9.

Metodi Ufficiali di Analisi dei Cereali. 1994. Serie Generale No. 186, 114.

Miao, M., B. Jiang and T. Zhang. 2009. Effect of pullulanase debranching and recrystallization on structure and digestibility of waxy maize starch. Carbohydr. Polym. 76: 214-221.

Michalcová, V., R. Dušinsky, M. Sabo, M. Al Beyroutiová, P. Hauptvogel, Z. Ivaničová and M. Švec. 2014. Taxonomical classification and origin of Kamut ${ }^{\circledR}$ wheat. Plant Syst. Evol. 300: 1749-1757.

Padalino, L., M. Mastromatteo, L. Lecce, S. Spinelli, A. Conte and M. A. Del Nobile. 2015. Effect of raw material on cooking quality and nutritional composition of durum wheat spaghetti. Int. J. Food Sci. Nutr. 66: 266-274.

Pasqualone, A., A. R. Piergiovanni, F. Caponio, V. M. Paradiso, C. Summo and R. Simeone. 2011. Evaluation of the technological characteristics and bread-making quality of alternative wheat cereals in comparison with common and durum wheat. Food Sci. Tech. Int. 17: 135-142.

Pérez-Jiménez, J. and J. L. Torres. 2011. Analysis of non-extractable phenolic compounds in foods: the current state of the art. J. Agric. Food Chem. 59: 12713-12724.
Rangel-Huerta, O. D., B. Pastor-Villaescusa, C. M. Aguilera and A. Gil. 2015. A systematic review of the efficacy of bioactive compounds in cardiovascular disease: Phenolic compounds. Nutrients. 29: 5177-216.

Springmann, M., H. C. J. Godfray, M. Rayner and P. Scarborough. 2016. Analysis and valuation of the health and climate change cobenefits of dietary change. Proc. Natl. Acad. Sci. 113: 4146-4151.

Trozzi, C., F. Raffaeli, A. Vignini, L. Nanetti, R. Gesuita and L. Mazzanti. 2019. Evaluation of antioxidative and diabetespreventive properties of an ancient grain, Kamut ${ }^{\circledR}$ khorasan wheat, in healthy volunteers. Eur. J. Nutr. 58: 151-161.

Van Hung, P. 2016. Phenolic compounds of cereals and their antioxidant capacity. Crit. Rev. Food Sci. Nutr. 56: 25-35.

Whitmee, S., A. Haines, C. Beyrer, F. Boltz, A. G. Capon, B. F. de Souza Dias, A. Ezeh, H. Frumkin, P. Gong, P. Head, R. Horton, G. M. Mace, R. Marten, S. S. Myers, S. Nishtar, S. A. Osofsky, S. K. Pattanayak, M. J. Pongsiri, C. Romanelli, A. Soucat, J. Vega and D. Yach. 2015. Safeguarding human health in the anthropocene epoch: Report of the rockefeller foundation-lancet commission on planetary health. Lancet. 386: 1973-2028.

Willett, W., J. Rockström, B.Loken, M.Springmann, T.Lang, S. Vermeulen, T. Garnett, D. Tilman, F. DeClerck, A. Wood, M. Jonell, M. Clark, L. J. Gordon, J. Fanzo, C. Hawkes, R. Zurayk, J. A. Rivera, W. De Vries, L. M. Sibanda, A. Afshin, A. Chaudhary, M. Herrero, R. Agustina, F. Branca, A. Lartey, S. Fan, B. Crona, E. Fox, V. Bignet, M. Troell, T. Lindahl, S. Singh, S. E. Cornell, K. S. Reddy, S. Narain, S. Nishtar and C. J. L. Murray. 2019. Food in the anthropocene: The EAT Lancet commission on healthy diets from sustainable food systems. Lancet. 393: 447-492.

Wrigley, C., I. Batey and D. Miskelly. 2016. Cereal Grains: Assessing and Managing Quality. $2^{\text {nd }}$ ed. Woodhead Publishing, United Kingdom. 